ROCZNIKI TEOLOGICZNE

Tom LXVI, zeszyt 5 - 2019

DOI: http://dx.doi.org/10.18290/rt.2019.66.5-8

VICENTE BOSCH

\title{
SANTIDAD LAICAL Y CARÁCTER TEOLÓGICO DE LA SECULARIDAD
}

\author{
SECULARITY HOLINESS \\ AND THEOLOGICAL CHARACTER OF SECULARITY
}

\begin{abstract}
What spirituality do lay people need today? There is a great need today to understand the theological meaning of the "secular character" - the characteristic "color" of lay people. The layman is a Christian called to unite with God, to holiness; someone who lives in the world and its structures, and from there is called to find God in ordinary life - family, work, social relations. If the mission of the Church is - along with the salvation of souls - to sanctify the world, one cannot continue to ignore the theological and apostolic nature of the daily work of lay people in the middle of the world. It is sanctified by God and sanctifying. It is therefore necessary to appreciate secularity - recognition of lay vocation and mission in the Church. The teaching of the Church also reminds that it is necessary to raise the awareness of pastors so that they can show lay faithful their call to renew the world in Christ.
\end{abstract}

Key words: layman; secularity; God's people; work; world; mission; sanctification; society.

A la pregunta ¿qué espiritualidad necesitan hoy los laicos?, mi respuesta arrancaría de la necesaria valoración de la vocación laical como camino de santidad, y de una adecuada comprensión del carácter teológico de la secularidad, nota distintiva de los fieles laicos. Estos son los dos pasos del proceso en el que integraré mis reflexiones, finalizadas en un tercer momento a modo de conclusión.

ViCENTE BOSCH - sacerdote, licenciado en derecho canónico y doctor en teología, profesor de la Universidad Pontificia Santa Croce; director de la revista „Annales Theologici”; dirección postal: Piazza di Sant'Apolinare 49; 00186 Roma; e-mail: bosch@pusc.it. 


\section{LA SANTIDAD DE LA VOCACIÓN CRISTIANA DE LOS FIELES LAICOS}

Ante todo, conviene recordar que ser laico es un modo de ser cristiano y presupone la ordinaria condición humana con sus valores y dificultades. El laico es un cristiano llamado a la unión con Dios; alguien que habita en el mundo y en sus estructuras, y desde allí es llamado a encontrar a Dios en la vida ordinaria -familia, trabajo, relaciones sociales-; llamado, en definitiva, a asumir la totalidad de propia existencia con el sentido y el valor conferidos por la fe cristiana. No podemos detenernos en considerar en qué consiste la vocación cristiana, pero resulta premisa ineludible afirmar que la vida espiritual cristiana precede todas sus modalidades de realización (laical, sacerdotal y vida consagrada). Por tanto, el fiel laico, ante todo, vive una existencia cristiana marcada por unas dimensiones constitutivas y un desarrollo, que recientemente resumí así: «es una vida 'trinitaria y filial' (Cristo nos ha hecho conocer al Padre, y la acción del Espíritu Santo conduce al cristiano a sentirse -y vivir como- hijo de Dios); es una vida 'cristocéntrica' (la santidad consiste en la plena identificación con Cristo, que incluye la participación en su misión); es una vida 'pneumatológica' (el Espíritu Santo es el artista que esculpe en el cristiano la imagen de Cristo); es una vida 'eclesial', litúrgica, apostólica, mariana (Cristo se une al cristiano en la Iglesia, y como una madre le alimenta con la Palabra y los sacramentos); es una vida 'histórica', encarnada (la intimidad con Dios no requiere un aislamiento de la realidad, no es un espiritualismo sin mundo; y, por último, es una vida 'escatológica', en tensión hacia una plenitud que solo se alcanzará en el más allá. Sin perder de vista estos elementos constitutivos de la vida cristiana, aludimos ahora al desarrollo de la vida espiritual, que fundamentalmente consiste en: el crecimiento en las virtudes teologales, que tienen por objeto directo 'creer a y en Dios', 'esperar en Dios' y 'amar a Dios'; el desarrollo de las virtudes humanas y de la humildad; el combate espiritual o lucha interior contra las tendencias desordenadas (mortificación y esfuerzo por percibir habitualmente la cercanía de Dios); y la vida de oración, que es medio indispensable para crecer en nuestra unión vital con Dios y no aparta del compromiso en el mundo y en la historia» ${ }^{1}$.

Con esta premisa sobre lo que es la existencia cristiana podemos ahora fijar nuestra atención en su modalidad laical, que tiene unos rasgos

\footnotetext{
${ }^{1}$ V. Bosch, La vocación cristiana laical: renovar el mundo con Cristo, "Scripta Theologica" 50 (2018), pp. 422-423.
} 
característicos propios: «una particular experiencia cristiana de lo humano y una especial sensibilidad hacia lo humano (podríamos hablar de una 'espiritualidad de la encarnación' en la que lo teologal fecunda las situaciones y tareas de la concreta existencia humana); un amor teologal al mundo (aprecio y estima de las realidades terrenas, de sus valores y destino); una valoración positiva de la vida ordinaria (capacidad de trascender lo normal de cada día, otorgando a esas tareas la grandeza del amor); competencia profesional y sentido de responsabilidad; conciencia de la ordenación a Dios de las realidades terrenas (un sentido teologal de las cosas que, al mismo tiempo, respete su naturaleza y leyes propias); y, finalmente, un acentuado sentido de la libertad personal (necesaria para decidir opciones profesionales, políticas, económicas, según su conciencia informada por la fe, y sin disolver su responsabilidad en la comunidad) $\rangle^{2}$.

a) Superar una noción restringida de vocación

En el prólogo o introducción de la exhortación apostólica Gaudete et Exsultate (en adelante, GaExs) el Papa Francisco da razón de su iniciativa: «Mi humilde objetivo es hacer resonar una vez más el llamado a la santidad [...] Porque a cada uno de nosotros el Señor nos eligió 'para que fuéramos santos e irreprochables ante él por el amor' $(E f 1,4) »(G a E x s$ 2); «Él nos quiere santos y no espera que nos conformemos con una existencia mediocre, aguada, licuada» (GaExs 1). Por su parte, el documento preparatorio de la XV Asamblea General Ordinaria del Sínodo de Obispos afirma que «la vocación al amor asume para cada uno una forma concreta en la vida cotidiana a través de una serie de opciones que articulan estado de vida (matrimonio, ministerio ordenado, vida consagrada, etc.), profesión, modalidad de compromiso social y político, estilo de vida, gestión del tiempo y del dinero, etc.» ${ }^{3}$. No pocas de las opciones señaladas -matrimonio, profesión, compromiso social y político, libre gestión del tiempo y dinero- tienen mucho que ver con la condición secular, que es la predominante en el Pueblo de Dios. Evidentemente, la 'vocación al amor' puede ser recibida, acogida y vivida en el matrimonio y en el ejercicio de una profesión civil que tiene la intención de dar gloria a Dios y servir a los demás. Sin embargo, se debe reconocer que, a pesar de los cincuenta años transcurridos desde el Concilio Vaticano, la vivencia de la condición laical con sentido vocacional es, todavía, poco frecuente. En general -y aunque no falten excepciones-, existe

\footnotetext{
${ }^{2}$ Ibídem, p. 423.

${ }^{3}$ SínOdo De los OBispos, Los jóvenes, la fe y el discernimiento vocacional. Documento preparatorio. Introducción, Libreria Editrice Vaticana, Città del Vaticano 2017, p. 6.
} 
en el sentir popular una fuerte inercia a ver en el sacerdocio y en la vida consagrada las 'verdaderas' vocaciones. Al constatar esta realidad, cabe preguntarse si la teología ha ahondado suficientemente en el contenido y consecuencias de la doctrina sobre la llamada universal a la santidad, expuesta con claridad en el capítulo quinto de la Constitución Lumen gentium. Y no solo: la pastoral de la Iglesia iha logrado transmitir con eficacia el sentido vocacional de toda existencia cristiana, consecuencia inmediata de esa doctrina? Solo cuando se es consciente de haber sido llamado se puede vivir la existencia como realización de una vocación. Por ello, resulta tarea insoslayable, en las actuales circunstancias, afirmar con fuerza el carácter vocacional de la experiencia cristiana laical ${ }^{4}$.

En Gaudete et Exsultate, Francisco afronta la cuestión dando dos pasos. Primero, superando el concepto restringido de vocación:

«Para ser santos no es necesario ser obispos, sacerdotes, religiosas o religiosos. Muchas veces tenemos la tentación de pensar que la santidad está reservada solo a quienes tienen la posibilidad de tomar distancia de las ocupaciones ordinarias, para dedicar mucho tiempo a la oración. No es así. Todos estamos llamados a ser santos viviendo con amor y ofreciendo el propio testimonio en las ocupaciones de cada día, allí donde cada uno se encuentra» (GaExs 14).

Y, posteriormente, subrayando el sentido vocacional de toda existencia cristiana: «Tú también necesitas concebir la totalidad de tu vida como una misión. Inténtalo escuchando a Dios en la oración y reconociendo los signos que él te da. Pregúntale siempre al Espíritu qué espera Jesús de ti en cada momento de tu existencia y en cada opción que debas tomar, para discernir el lugar que eso ocupa en tu propia misión» (GaExs 23). Efectivamente, el «nexo entre vocación y misión remite necesariamente a la conformidad de nuestra voluntad con la voluntad divina. El cristiano se santifica en la medida en que su fe, esperanza y caridad actúan en el cumplimiento fiel y diario de la voluntad de Dios. En otras palabras, lo que perfecciona y conduce a plenitud la personalidad humana es la aceptación del estilo de vida, condiciones personales, e inserción en el mundo que Dios elige para cada uno. El hombre se 'realiza' en el libre consentimiento al querer de Dios, que, para el hombre

\footnotetext{
${ }^{4}$ «Reto pastoral en nuestros días es hacer entender que la condición laical de la mayoría de los cristianos no es fruto de la casualidad ni de la necesidad (no tener vocación al sacerdocio o a la vida religiosa), sino opción personal e identificación existencial que, apoyadas en la fuerza y virtualidad del bautismo, se convierte en modalidad de seguimiento de Cristo, en camino de santidad» (V. BosCH, Santificar el mundo desde dentro. Curso de espiritualidad laical, BAC, Madrid 2017, p. 14).
} 
de fe, es siempre lo mejor» ${ }^{5}$. También el Santo Padre insiste en esta idea: «No tengas miedo de la santidad. No te quitará fuerzas, vida o alegría. Todo lo contrario, porque llegarás a ser lo que el Padre pensó cuando te creó y serás fiel a tu propio ser» (GaExs 32); «No tengas miedo de dejarte guiar por el Espíritu Santo. La santidad no te hace menos humano, porque es el encuentro de tu debilidad con la fuerza de la gracia» (GaExs 34). En definitiva, podemos concluir señalando que la vocación es: universal -en sentido subjetivo, todos son llamados; y objetivo, pues todas las circunstancias de la vida pueden ser lugar y medio de santificación ${ }^{6}-$; omnicomprensiva -abraza la vida entera en todas sus facetas-; 'realizadora' de la persona; e implica siempre una misión, una función o tarea que realizar como miembro del Cuerpo de Cristo que es la Iglesia.

b) La misión de los laicos en la Iglesia

La doctrina conciliar sobre los laicos expuesta en el capítulo cuarto de Lumen gentium arranca con la afirmación de que ellos tienen la común vocación cristiana, pero con una modalidad y características propias (cfr. n. 30), que son descritas en el número siguiente:

\begin{abstract}
«A los laicos corresponde, por propia vocación, tratar de obtener el reino de Dios gestionando los asuntos temporales y ordenándolos según Dios. Viven en el siglo, [... y] Allí están llamados por Dios, para que, desempeñando su propia profesión guiados por el espíritu evangélico, contribuyan a la santificación del mundo como desde dentro, a modo de fermento» ${ }^{7}$.
\end{abstract}

No debe pasar desapercibido que este texto utiliza un lenguaje vocacional -'corresponde, por propia vocación', 'allí están llamados por Dios'-, señalando también el origen divino de la misión confiada de santificar el mundo. Evidentemente, esta misión ha sido confiada por Cristo a la totalidad de la Iglesia:

«La obra de la redención de Cristo, que de suyo tiende a salvar a los hombres, comprende también la restauración incluso de todo el orden temporal. Por tanto, la misión de la Iglesia no es sólo anunciar el mensaje de Cristo y su gracia a los hombres, sino también el impregnar y perfeccionar todo el orden temporal con el espíritu evangélico» ${ }^{8}$.

${ }^{5} \mathrm{~V}$. Bosch, Llamados a ser santos. Historia contemporánea de una doctrina, Palabra, Madrid 2008, p. 203.

${ }^{6}$ Cfr. F. OCARIZ, Vocación a la santidad en Cristo y en la Iglesia, en M. Belda, J. Escudero, J.L. Illanes, P. O’Callaghan (eds.), Santidad y mundo, Eunsa, Pamplona 1996, p. 41.

${ }^{7}$ Concilio Vaticano II, Const. Lumen gentium (21.11.1964), n. 31.

8 ÍDEM, Decr. Apostolicam actuositatem (18.12.1965), n. 5. 
Es decir, la misión de la Iglesia es como una moneda con dos caras: una es la salvación de las almas, y la otra la santificación del mundo. Esta última consiste en purificar y renovar el mundo, conducirlo hacia Dios. Y todos en el Pueblo de Dios -sacerdotes, religiosos y laicos- participan en esa responsabilidad y misión, aunque con modalidades diversas. La modalidad laical tiene, sin embargo, una particular relevancia:

«en el cumplimiento de este deber universal corresponde a los laicos el lugar más destacado. Por ello, con su competencia en los asuntos profanos y con su actividad elevada desde dentro por la gracia de Cristo, contribuyan eficazmente a que los bienes creados, de acuerdo con el designio del Creador y la iluminación de su Verbo, sean promovidos, mediante el trabajo humano, la técnica y la cultura civil, para utilidad de todos los hombres sin excepción» ${ }^{9}$.

En definitiva $-y$ es a donde queríamos llegar-, si la misión de la Iglesia consiste, junto con la salvación de las almas, en la santificación del mundo, no es posible seguir ignorando el carácter teologal y eclesial del trabajo santificado y santificador de los laicos en medio del mundo. Con razón insistió en esta idea san Juan Pablo II: «el ser y el actuar en el mundo son para los fieles laicos no sólo una realidad antropológica y sociológica, sino también, y específicamente, una realidad teológica y eclesial» ${ }^{10}$.

\section{EL CARÁCTER TEOLÓGICO DE LA SECULARIDAD}

El mundo no es simplemente el escenario en el que los cristianos actúan, el ámbito en el que necesariamente se mueven (por fuerza están en el mundo, pues de lo contario estarían en la fantasía o en la eternidad). El mundo es mucho más: es el fruto de la acción creadora Dios, herido por el pecado, necesitado de ser purificado por la gracia y de ser transformado y reconducido hacia Dios. La secularidad indica, por tanto, la responsabilidad que tiene la Iglesia de renovar el mundo con Cristo. Y el fiel laico cumple esa misión de la Iglesia cuando utiliza las realidades terrenas como medio para llegar a Dios, y, mediante su actividad laboral, las ofrece a Dios como culto espiritual: «la espera ansiosa de la creación anhela la manifestación de los hijos de Dios. Porque la creación se ve sujeta a vanidad, no por su voluntad, sino por quien la sometió, con la esperanza de que también la misma

\footnotetext{
9 ÍDEM, Const. Lumen gentium, n. 36.

${ }^{10}$ San Juan Pablo II, Ex. ap. Christifideles laici (30.12.1988), n. 15.
} 
creación será liberada de la esclavitud de la corrupción, para participar de la libertad gloriosa de los hijos de Dios» $(R m$ 8, 19-21). El beato Álvaro del Portillo, perito conciliar y padre sinodal en la Asamblea ordinaria de 1987, sobre la vocación y misión del laico en la Iglesia y en el mundo, afirmaba en el inmediato postconcilio:

\begin{abstract}
«La secularidad entra en la definición de laico en la medida en que la Iglesia advierte claramente que la suerte del mundo no le es ajena, e invita al cristiano a mirarlo con amor. [...] La secularidad no es, pues, simplemente una nota ambiental o circunscriptiva, sino una nota positiva y propiamente teológica. Hasta que vengan el nuevo cielo y la nueva tierra, la inserción del hombre dentro del mundo es absolutamente necesaria, es voluntad divina, [...]. Pues bien, esta inserción del hombre en lo temporal, en las tareas de dominio y transformación del mundo, es la secularidad $»^{11}$.
\end{abstract}

Efectivamente, el mismo «Cristo en su andar terreno inició la gran tarea de purificación y renovación de las cosas creadas: trabajó por casi veinte años -tiempo también redentor- en un modesto oficio, dominando y perfeccionando la materia prima; las incontables curaciones milagrosas que nos narran los Evangelios sanaban concretas imperfecciones de la naturaleza; [...] $\mathrm{y}$, por último, Cristo en la Cruz constituye el paradigma de la secularidad, entendida como voluntaria inmersión en el mundo para renovarlo y llevarlo hacia Dios» ${ }^{12}$. Ya afirmó Pablo VI en 1972 que la dimensión secular de la Iglesia «hunde su raíz en el misterio del Verbo Encarnado» ${ }^{13}$.

Pues bien, a mi entender, «del carácter teologal y eclesial de la secularidad se escribe y se habla poco, como si la profesionalidad y eficiencia de un médico, un agricultor, un ingeniero o un taxista solo afectara a su esfera privada y pública de ciudadano, y nada tuviera que ver con su condición cristiana y de miembro de la Iglesia que, precisamente, tiene por misión santificarse en y santificar esa actividad, ordenándola hacia Dios» ${ }^{14}$. El carácter eclesial de la acción santificadora del mundo que realizan los laicos no parece haber sido suficientemente reconocida y profundizada. En los

11 Beato Álvaro del Portillo, Fieles y laicos en la Iglesia, Eunsa, Pamplona 199132, pp. 184-185.

12 V. Bosch, La vocación cristiana laical, pp. 416-417.

${ }^{13}$ San Pablo VI, Discurso a los representantes de los institutos seculares sacerdotales y laicales, 2.02.1972.

${ }^{14}$ V. Bosch, Christifideles laici y el beato Álvaro del Portillo, "Scripta Theologica" 47(2015), p. 333. [Existe una versión polaca de este estudio: Christifideles laici $i$ bl. beato Álvaro del Portillo, w: P. Roszak, P.P. OrLowski (red.), Radość stużby Bp Álvaro del Portillo (19141994), Uniwersytet Mikołaja Kopernika, Toruń 2016, 101-132]. 
decenios posconciliares, se tendió, con algo de superficialidad, a distribuir la vocación y misión del laico en 'la Iglesia y en el mundo' en dos ámbitos paralelos, aplicando un dualismo en el ser y actuar del laico, que alternativamente intervendría o en la Iglesia o en el mundo, como si fueran realidades opuestas o en insanable antinomia. Una cierta inercia de la literatura teológica y pastoral ha llevado a identificar la misión del laico en la Iglesia con el ejercicio de los ministerios laicales y con su responsable y necesaria participación en las estructuras organizativas y administrativas eclesiásticas, dejando en el olvido su actuación en el mundo, como si ésta se desarrollara en la periferia de la vida de la Iglesia. Esta visión, imbuida de clericalismo, relega a función marginal en la Iglesia la santificación de las estructuras temporales (familia, sociedad, cultura, trabajo, etc.). En el corazón de la vida de la Iglesia se encuentra, como hemos visto, la misión de renovar el mundo y conducirlo hacia Dios. Del mismo modo que no se duda de la eclesialidad del ejercicio del diaconado permanente, ni de la función catequética de la madre que enseña a sus hijos las primeras oraciones, tampoco se debería dudar de la eclesialidad del trabajo realizado por un obrero o un profesional que busca santificarse con su actividad, sirviendo a los demás, mejorando el mundo y alabando a Dios. Cuando se ejerce cualquier profesión con perfección humana y sobrenatural (caridad e intención) se está purificando el correspondiente ámbito de esas realidades terrenas y están siendo conducidas a Dios. En esto consiste el carácter teológico de la secularidad, y a esto se refería san Juan Pablo II cuando recordaba en Christifideles laici n. 15 que la acción de los fieles laicos en el mundo no es sólo una realidad sociológica o antropológica. En otras palabras, el trabajo santificado de los laicos en medio del mundo, que bajo el influjo de la gracia promueven la justicia y el bien común en su deseo de llevar las cosas creadas hacia Dios, tiene por su misma naturaleza carácter eclesial, sin ser una actividad eclesiástica (conviene tener muy en cuenta la distinción entre eclesial y eclesiástica, entendida ésta última como actividad o función de la jerarquía o eclesiásticos). Si se afirma que es misión de la Iglesia «la restauración de todo el orden temporal» (Apostolicam actuositatem, 5), se debe reconocer también: 1) el carácter eclesial del trabajo santificado que los fieles laicos llevan a cabo desde la entraña del mundo; y 2) que esa función o tarea responde a una misión a la que muchos están llamados, constituyendo, por tanto, una vocación divina. 
a) Un necesario golpe de timón en la valoración de la secularidad

En el origen de una falta de reconocimiento del carácter eclesial del compromiso del laico en el mundo se puede detectar el prejuicio clerical del pensar que el cristiano es más cristiano en la medida en que se involucra en funciones y tareas eclesiásticas. Lo había denunciado hace medio siglo san Josemaría Escrivá de Balaguer, promotor de una espiritualidad laical basada en la santificación del trabajo profesional: «Hay que rechazar el prejuicio de que los fieles corrientes no pueden hacer más que limitarse a ayudar al clero, en apostolados eclesiásticos. [...] El modo específico de contribuir los laicos a la santidad y al apostolado de la Iglesia es la acción libre y responsable en el seno de las estructuras temporales» ${ }^{15}$. Esta idea -de origen carismático y con visos de profecía - la vemos recogida, reiterada y aumentada, casi medio siglo después, en un texto relativamente reciente del Papa Francisco:

«El clericalismo lleva a la funcionalización del laicado; tratándolo como 'mandaderos', coarta las distintas iniciativas, esfuerzos y hasta me animo a decir, osadías necesarias para poder llevar la Buena Nueva del Evangelio a todos los ámbitos [...]. Muchas veces hemos caído en la tentación de pensar que el laico comprometido es aquel que trabaja en las obras de la Iglesia y/o en las cosas de la parroquia o de la diócesis y poco hemos reflexionado cómo acompañar a un bautizado en su vida pública y cotidiana; cómo él, en su quehacer cotidiano, con las responsabilidades que tiene se compromete como cristiano en la vida pública. Sin darnos cuenta, hemos generado una élite laical creyendo que son laicos comprometidos solo aquellos que trabajan en cosas 'de los curas' y hemos olvidado, descuidado al creyente que muchas veces quema su esperanza en la lucha cotidiana por vivir la fe» ${ }^{16}$.

El dinamismo «de salida» que el Papa Francisco quiere provocar en una Iglesia misionera requiere un mayor compromiso de los fieles laicos en lograr que los valores cristianos penetren el mundo social, político y económico. Confesión de la fe y compromiso social van de la mano. Lo afirma claramente Francisco al señalar dos errores nocivos o «ideologías que mutilan el corazón del Evangelio»: un compromiso social sin unión personal con el Señor (cfr. GaExs 100), o una fe que considera el compromiso social superficial, mundano e inmanentista (cfr. GaExs 101-103).

${ }^{15}$ SAn Josemaria Escriva de BAlaguer, Conversaciones con Mons. Escrivá de Balaguer, nn. 34/a y 59/b, ed. crítico-histórica preparada por J.L. Illanes y A. MENDiZ, Rialp, Madrid 2012, pp. 243 y 303.

${ }^{16}$ Francisco, Carta al Card. Ouellet, Presidente de la Pontificia Comisión para América Latina, 19.03.2016. 


\section{b) Una pastoral revitalizadora del compromiso cristiano en el mundo}

Uno de los grandes desafíos pastorales que tiene ante sí la Iglesia en nuestros días es lograr concienciar a esa multitud de fieles laicos, cristianos 'de a pie', de haber recibido una vocación divina y de estar llamados a santificarse en su ambiente profesional, purificando con su actuar cristiano las realidades terrenas y conduciendo, así, el mundo hacia Dios. La potencia evangelizadora de los laicos está todavía por descubrir y hacer explotar. Los fieles laicos, por estar colocados en la entraña del mundo para actuar «desde dentro, a modo de fermento», no pueden prescindir, en sus relaciones con Dios, de sus obligaciones de estado familiar y laboral, ni de su inserción en los ámbitos cultural, socio-político, económico, etc. Todo eso constituye parte importante de su vida espiritual, de su relación con Cristo, marcándola y condicionándola profundamente. Se podría afirmar que la vida espiritual del laico se desarrolla entre dos coordenadas o componentes irrenunciables: la coordenada vertical de comunión con Dios, de unión a Cristo por la fe y la caridad; y la horizontal, de inserción en las realidades temporales y participación en las actividades terrenas.

Como se puede intuir, en la valoración y promoción de la auténtica vocación de los laicos y de su misión peculiar en la Iglesia juegan un papel importante la catequesis y el acompañamiento espiritual. Las Iglesias particulares y comunidades cristianas deberían renovar sus esfuerzos para transmitir a los fieles laicos el sentido vocacional de su existencia, y esto requiere una oferta de formación que sea atractiva y eficaz (cursos de teología para laicos, conferencias, debates, etc. en locales acogedores, limpios, caldeados). Además, como todo cristiano, también el laico necesita ser acompañado para vivir su vocación y misión. Es verdad que la comunidad constituye siempre un importante apoyo en el camino, pero no basta. Se necesita también el consejo personalizado, la sugerencia práctica, una luz capaz de alumbrar en las particulares circunstancias de cada persona. La modalidad de este acompañamiento puede variar: desde la confesión frecuente con un mismo sacerdote si se ve conveniente, hasta las conversaciones de dirección espiritual, en un clima de fraternidad y libertad, con una persona experta (sacerdote, religioso o laico). En conclusión, la función de los pastores en la promoción de la vocación y misión de los fieles laicos se puede resumir en ayudarles a vivir su fe en las condiciones ordinarias de su existencia, y en fomentar su compromiso en una efectiva evangelización y transformación de la sociedad. 


\title{
3. A MODO DE CONCLUSIÓN: UNA DOCTRINA NUEVAMENTE CONFIRMADA
}

Las dos coordenadas a las que acabamos de hacer referencia -unión con Dios e inserción en las realidades temporales- constituyen el núcleo de la santidad laical, los elementos indispensables para que los laicos vivan su vocación y misión en la Iglesia. La primera de ellas -la unión con Diosaunque resulte obvia no puede darse por descontada en la experiencia cristiana laical y, por eso, el Papa Francisco la subraya:

\begin{abstract}
«Esa misión tiene su sentido pleno en Cristo y solo se entiende desde él. En el fondo la santidad es vivir en unión con él los misterios de su vida. Consiste en asociarse a la muerte y resurrección del Señor de una manera única y personal, en morir y resucitar constantemente con él. [...] Por lo tanto, 'la santidad se mide por la estatura que Cristo alcanza en nosotros, por el grado como, con la fuerza del Espíritu Santo, modelamos toda nuestra vida según la suya'» (GaExs 20-21).
\end{abstract}

En ese estar unido a Cristo como el sarmiento a la vid (cfr. Jn 15,1-5), el fiel laico, como todo cristiano, necesita de la oración: «aunque parezca obvio, recordemos que la santidad está hecha de una apertura habitual a la trascendencia, que se expresa en la oración y en la adoración. El santo es una persona con espíritu orante, que necesita comunicarse con Dios. Es alguien que no soporta asfixiarse en la inmanencia cerrada de este mundo, [...]. No creo en la santidad sin oración» (GaExs 147). Y junto a la vida de oración se precisa una lucha decidida contra los enemigos del alma y para crecer en las virtudes:

\begin{abstract}
«La vida cristiana es un combate permanente. Se requieren fuerza y valentía para resistir las tentaciones del diablo y anunciar el Evangelio» (GaExs 158); «nuestro camino hacia la santidad es también una lucha constante. Quien no quiera reconocerlo se verá expuesto al fracaso o a la mediocridad. [...] En este camino, el desarrollo de lo bueno, la maduración espiritual y el crecimiento del amor son el mejor contrapeso ante el mal. Nadie resiste si opta por quedarse en un punto muerto» (GaExs 162-163).
\end{abstract}

Con esta premisa de la unión con Dios de todo cristiano, afrontamos ahora la inserción en la realidades temporales -la índole secular- propia de los fieles laicos. Aunque es obvio que en Gaudete et Exsultate el Papa se dirige a todos los miembros del Pueblo de Dios, en determinados momentos tiene muy en primer plano a los fieles laicos. Principalmente cuando habla de la sociedad que necesita ser restaurada y renovada por los principios del 
Evangelio. Por ejemplo, al comentar la bienaventuranza de los que tienen hambre y sed de justicia, afirma:

\begin{abstract}
«La realidad nos muestra qué fácil es entrar en las pandillas de la corrupción, formar parte de esa política cotidiana del 'doy para que me den', donde todo es negocio. Y cuánta gente sufre por las injusticias, cuántos se quedan observando impotentes cómo los demás se turnan para repartirse la torta de la vida. Algunos desisten de luchar por la verdadera justicia, y optan por subirse al carro del vencedor. Eso no tiene nada que ver con el hambre y la sed de justicia que Jesús elogia» (GaExs 78).
\end{abstract}

Efectivamente, corresponde a los fieles laicos santificar el mundo desde dentro, liberando la creación de la esclavitud de la corrupción (cfr. $R m$ 8,21). También, al comentar la bienaventuranza de los perseguidos por causa de la justicia, se entreve la situación de muchos laicos puestos en el punto de mira de una persecución solapada que busca amordazar sus conciencias, torpedear sus convicciones y arrinconarles en el bienestar, el lucro, el placer, el egoísmo destructor de la familia y de la vida misma: son persecuciones sufridas «de un modo más sutil, a través de calumnias y falsedades. [...] Otras veces se trata de burlas que intentan desfigurar nuestra fe y hacernos pasar como seres ridículos. Aceptar cada día el camino del Evangelio aunque nos traiga problemas, esto es santidad» (GaExs 94).

El sacerdocio común de los fieles laicos se ejercita también mediante el trabajo profesional bien hecho que, ofrecido a Dios como sacrificio espiritual agradable a Dios por Jesucristo (cfr. $1 P$ 2,5), es medio de santificación, como confirma Francisco: «Me gusta ver la santidad [...] en esos hombres y mujeres que trabajan para llevar el pan a sus casas» (GaExs 7); «¿Eres un trabajador? Sé santo cumpliendo con honradez y competencia tu trabajo al servicio de los hermanos. [...] ¿Tienes autoridad? Sé santo luchando por el bien común y renunciando a tus intereses personales» (GaExs 14).

Esa connatural inserción de los fieles laicos en la entraña de la sociedad aparece reflejada en la exhortación, en los párrafos agrupados bajo el título «la actividad que santifica»: "Como no puedes entender a Cristo sin el reino que él vino a traer, tu propia misión es inseparable de la construcción de ese reino: 'Buscad sobre todo el reino de Dios y su justicia' (Mt 6,33). Tu identificación con Cristo y sus deseos, implica el empeño por construir, con él, ese reino de amor, justicia y paz para todos» (GaExs 25). Además, Francisco pone en alerta ante el peligro de un espiritualismo que inhiba de la acción: 
«No es sano amar el silencio y rehuir el encuentro con el otro, desear el descanso y rechazar la actividad, buscar la oración y menospreciar el servicio. [...] Somos llamados a vivir la contemplación también en medio de la acción, y nos santificamos en el ejercicio responsable y generoso de la propia misión. [...] a veces tenemos la tentación de relegar [...] el compromiso en el mundo a un lugar secundario, como si fueran 'distracciones' en el camino de la santificación y de la paz interior» (GaExs 26-27).

Del mismo modo, el matrimonio de los fieles laicos es confirmado como camino de santidad: «Me gusta ver la santidad en el pueblo de Dios paciente: a los padres que crían con tanto amor a sus hijos» (GaExs 7); «¿Estás casado? Sé santo amando y ocupándote de tu marido o de tu esposa, como Cristo lo hizo con la Iglesia. [...] ¿Eres padre, abuela o abuelo? Sé santo enseñando con paciencia a los niños a seguir a Jesús» (GaExs 14).

En definitiva, el Papa Francisco - como hizo san Juan Pablo II al inicio del nuevo milenio- desea de nuevo «poner la programación pastoral bajo el signo de la santidad» ${ }^{17}$. Una intención cargada de consecuencias entre las que destaca la necesidad de reconocer la vocación y misión de los laicos en la Iglesia, el carácter teológico y eclesial de su actividad en medio del mundo, y de concienciar a los pastores a saber desvelar a los fieles laicos su llamada a renovar el mundo con Cristo.

\section{BIBLIOGRAFIA}

Álvaro del Portillo, Beato, Fieles y laicos en la Iglesia, Eunsa, Pamplona $1991^{3}$.

Belda, M., Escudero, J., Illanes, J.L., O’Callaghan, P. (eds.), Santidad y mundo, Eunsa, Pamplona 1996.

Bosch, V., Christifideles laici y el beato Álvaro del Portillo, "Scripta Theologica" 47(2015), p. 333 [= versión polaca de este estudio: Christifideles laici $i$ bt. Álvaro del Portillo, w: P. RoszaK, P.P. OrLowski (red.), Radość stużby Bp. Álvaro del Portillo (1914-1994), Torun 2016, 101-132].

Bosch, V., La vocación cristiana laical: renovar el mundo con Cristo, "Scripta Theologica" 50 (2018), pp. 422-423.

Bosch, V., Santificar el mundo desde dentro. Curso de espiritualidad laical, BAC, Madrid 2017.

Concilio Vaticano II, Const. Lumen gentium (21.11.1964).

Concilio Vaticano II, Decr. Apostolicam actuositatem (18.11.1965).

Francisco, Carta al Card. Ouellet, Presidente de la Pontificia Comisión para América Latina (19.03.2016).

Josemaría Escrivá de Balaguer, SAn, Conversaciones con Mons. Escrivá de Balaguer, nn. 34/a y 59/b, ed. crítico-histórica preparada por J.L. ILLANES y A. MÉNDIZ, Rialp, Madrid 2012.

\footnotetext{
${ }^{17}$ San Juan Pablo II, Carta ap. Novo millennio ineunte (6.01.2001), n. 31.
} 
JUAN PABlo II, SAN, Carta ap. Novo millennio ineunte (6.01.2001).

JuAn PABlo II, SAn, Ex. ap. Christifideles laici (30.12.1988).

OCÁRIZ, F., Vocación a la santidad en Cristo y en la Iglesia, en M. BELDA, J. Escudero, J.L. Illanes, P. O'Callaghan (eds.), Santidad y mundo, Eunsa, Pamplona 1996.

PABlO VI, SAN, Discurso a los representantes de los institutos seculares sacerdotales y laicales (2.02.1972).

Sínodo de los OBISpos, Los jóvenes, la fe y el discernimiento vocacional. Documento preparatorio. Introducción, Libreria Editrice Vaticana, Città del Vaticano 2017.

\section{ŚWIĘTOŚĆ ŚWIECKICH I CHARAKTER TEOLOGICZNY ŚWIECKOŚCI}

\section{STRESZCZENIE}

Jakiej duchowości potrzebują dzisiaj świeccy? Istnieje dzisiaj wielka potrzeba zrozumienia teologicznego znaczenia „charakteru świeckiego” - specyficznego kolorytu ludzi świeckich. Laik jest chrześcijaninem powołanym do zjednoczenia z Bogiem, do świętości; ktoś, kto żyje w świecie i jego strukturach, a stamtąd jest wezwany do znalezienia Boga w zwykłym życiu - rodziny, pracy, relacji społecznych. Jeśli misja Kościoła polega - wraz ze zbawieniem dusz - na uświęceniu świata, nie można nadal ignorować teologicznego i apostolskiego charakteru codziennej pracy ludzi świeckich pośrodku świata. Jest ona bowiem uświęcona przez Boga oraz uświęcająca. Niezbędne jest zatem docenienie świeckości - uznania powołania i misji świeckich w Kościele. Nauczanie Kościoła przypomina również, że niezbędne jest podniesienie świadomości pasterzy, aby umieli ukazywać wiernym świeckim ich wezwanie do odnowienia świata w Chrystusie.

Słowa kluczowe: laikat; świeckość; lud Boży; praca; świat; misja; uświęcenie; społeczeństwo. 